\title{
AS TECNOLOGIAS DA INFORMAÇÃO E COMUNICAÇÃO (TICs) NO CONTEXTO DAS PRÁTICAS PEDAGÓGICAS NA SALA DE RECURSOS MULTIFUNCIONAIS
}

\author{
INFORMATION AND COMMUNICATION TECHNOLOGIES (ICTS) IN THE CONTEXT OF \\ PEDAGOGICAL PRACTICES IN THE MULTIFUNCTIONAL RESOURCE ROOM
}

\author{
Mayra Ferreira Barreto \\ Universidade Federal de Sergipe, Sergipe, SE, Brasil. E-mail: mayra.barreto@outlook.com
}

DOI: https://doi.org/10.46550/amormundi.v2i5.99

Recebido em: 27.06.2021

Aceito em: 23.07.2021

\begin{abstract}
Resumo: A presente pesquisa foi elaborada para servir como trabalho de conclusão de curso da especialização em "Atendimento Educacional Especializado", ofertado pela Universidade Cândido Mendes (UCM), sob a orientação do professor Ms. Jan Carlos Dias de Santana. O trabalho apresenta reflexóes a respeito da utilização do computador e da internet como ferra-menta pedagógica na Sala de Recursos Multifuncionais (SRM), com a finalidade de compre-ender de que forma essas Tecnologias da Informaçáo e Comunicaçáo (TICs) podem facilitar o processo de aprendizagem de alunos com necessidades especiais. $\mathrm{O}$ trabalho tem como mo-tivaçáo valorizar às (TICs) como instrumentos que possibilitam à autonomia e à independência de estudantes da Educação Especial. Para realização dos objetivos almejados, a pesquisa utilizou os estudos de Alarcáo (2011), Oliveira e Nascimento (2014), Santos e França (2014), Buniotti (2014), Fonseca (2015), Bravo (2016) e Fonseca (2017). Espera-se com este trabalho contribuir para o campo da educação especial e inclusiva, pois ainda são poucas as publicaçôes nessa área de conhecimento.
\end{abstract}

Palavras-chave: Tecnologias de Informação e Comunicação. Computador. Internet. Sala de Recursos Multifuncionais (SRM).

Absract: This research was designed to serve as the conclusion of a specialization course in "Special-ized Educational Service", offered by the Cândido Mendes University (UCM), under the guidance of Professor Ms. Jan Carlos Dias de Santana. The work presents reflections on the use of the computer and the internet as a pedagogical tool in the Multifunctional Resource Room (SRM), in order to understand how these Information and Communication Technolo-gies (ICTs) can facilitate the learning process of students with special needs. The work is mo-tivated by valuing (ICTs) as instruments that enable the autonomy and independence of Spe-cial Education students. To achieve the desired objectives, the research used the studies by Alarcão (2011), Oliveira and Nascimento (2014), Santos and França (2014), Buniotti (2014), Fonseca (2015), Bravo (2016) and Fonseca (2017). It is hoped that this work will contribute to the field of special and inclusive education, as there are still few publications in this area of knowledge.

Keywords: Information and Communication Technologies. Computer. Internet. Multifunctional Resource Room (SRM). 


\section{Introduçáo}

esde o início da segunda década do século XXI o Brasil vivencia uma tendência à
propagação de equipamentos de Tecnologias de Informaçáo e Comunicaçáo (TICs). Segundo dados do IBGE (2019), "a internet chega a oito em cada dez domicílios do País, sendo utilizada em 82,7\% dos domicílios brasileiros no ano de 2019. Entre os brasileiros com 10 anos ou mais de idade, a utilização da internet subiu de 74,7\%, em 2018, para 78,3\%, em 2019” (IBGE, 2019). Sendo assim, a nossa sociedade está cada vez mais conectada, seja através de tablet, smartfone, notebook, computador ou outras tecnologias digitais. Essas facilidades tecnológicas possibilitam o acesso às inúmeras informações, é o que os especialistas chamam da "Era da Informação".

Na chamada "Era da Informação" a internet vem modificando muitos aspectos das nossas vidas, a exemplo: das formas como nos relacionamos com as pessoas, os nossos comportamentos, a forma como escrevemos, nos comunicamos, a forma de trabalho, de busca e acesso às informaçóes. Ela também representou uma mudança significativa no que diz respeito tanto à acumulaçáo e acesso a informaçóes, dados e conhecimentos. Com isso, náo podemos ignorar a importância da internet no dia a dia das pessoas, principalmente dos jovens, que desde cedo estão inseridos nesse mundo da informação digital e que têm a necessidade de incorporação dessas tecnologias na sua aprendizagem.

A internet é uma importante ferramenta de aprendizado na sala de aula. Ela possibilita que as atividades didáticas sejam mais dinâmica, atrativas, favorecendo as interaçôes e trocas de experiências entre professores e alunos. Por meio da internet, os estudantes podem pesquisar em sites didáticos, realizar videoconferências, acessar livros eletrônicos, blogs, vídeos, fóruns sobre temas abordados em aula e jogos digitais. $\mathrm{O}$ discente pode ter acesso também a sites de visitas virtuais como: museus, arquivos, bibliotecas, obras de artes, sala de exposiçóes, ou seja, uma infinidade de recursos didáticos. Dessa forma a internet favorece a interatividade e a ampliaçáo de habilidades cognitivas, fazendo com que o estudante produza conhecimento, desenvolva autonomia e motivação na sala de aula.

Com todas as vantagens apresentadas com o uso da internet no ensino, as instituiçóes escolares devem proporcionar condiçóes para que os alunos sejam capazes de aprender nesse ambiente e/ou de incluí-los digitalmente. Assim como os professores devem conhecer e saber usar os recursos digitais, para orientar os estudantes e fazer relaçóes entre os conteúdos estudados. Mas, infelizmente, em muitas escolas no Brasil, principalmente as instituiçôes públicas, persistem dificuldades e resistências às inovaçóes tecnológicas. Sendo assim presenciamos o ensino passado para os alunos pelo método tradicional (aula expositiva, limitação aos manuais didáticos, métodos de avaliçóes excludentes etc.) causando desinteresse por boa parte dos estudantes que não tem o hábito de leitura, não têm interesse em assistir as aulas expositivas, e que não se envolvem com as atividades propostas pelo professor, com métodos já ultrapassados.

Além disso, muitas escolas brasileiras não possuem laboratórios de informática com acesso à internet ou quando possuem, há alguma resistência em usá-las por parte do professor. Outra questão que devemos considerar são os docentes que fazem parte de geraçôes anteriores e que não nasceram na era digital, mesmo aprendendo a lidar com a tecnologia, sentem ainda muitas dificuldades em aprender e utilizá-las na sala de aula. De acordo com Guimarães (2017) 
"muitos professores, ainda que reconheçam a importância da necessidade de aperfeiçoamento, permanecem imersos em outras práticas, realizadas por meios educativos convencionais" (GUIMARÁES, 2017, p. 365). Desta maneita, embora muitos professores utilizem recursos da internet no seu cotidiano escolar como e-mails, sites de pesquisas, redes sociais, muitos profissionais da educação não costumam a fazer reflexôes sobre recursos digitais.

Sendo assim, a função dos professores de Educação Básica é sempre desenvolver nos alunos os limites, as possibilidades e conceitos básicos acerca do tema TICs. O papel do educador na sociedade da informação não deve ser um educador centralizador e o único detentor de saber. Mas sim, um docente que possua criatividade, reflexão diante de novas propostas e atividades, ou seja, um facilitador do conhecimento. É nesse contexto que o acesso à rede mundial de computadores deve ser ampliado e facilitado nas escolas. De acordo com Alarcão, “(...) a capacidade de interagir com o conhecimento de forma autônoma, flexível e criativa é a melhor preparação para vivência no nosso mundo supercomplexo, incerto, sempre pronto a exigir novo saberes, inspiradores de novas açôes" (ALARCÃO, 2011, p.32).

Diante do exposto, partiremos do seguinte questionamento: em que medida o uso do computador e da internet podem contribuir para a melhoria do processo aprendizagem de alunos com necessidades especiais?

Ao longo da pesquisa pode-se perceber a importância do docente em conhecer os limites e as possibilidades das tecnologias das informaçóes na aprendizagem do aluno, com o objetivo de melhorar a qualidade da educação. Dito isto, a utilizaçáo do computador e da internet no dia a dia da escola deve ocorrer de forma integrada ao Projeto Político Pedagógico (PPP), a metodologia do professor, e a organização das suas aulas e dos espaços que devem ser planejados e adaptados às necessidades dos alunos.

\section{Metodologia}

Para alcançar os objetivos almejados, a opção foi por uma pesquisa de caráter qualitativo e foi desenvolvida a partir da realização de revisão bibliográfica. O trabalho utilizou como instrumentos de coleta de dados: o uso de livros, artigos científicos, revistas científicas e anais de congressos. Dessa maneira, a pesquisa foi dividida nas seguintes fases: identificação do tema; levantamento da questão de pesquisa; construção de fichamentos dos textos lidos e produção escrita dos dados analisados.

\section{Resultados e discussáo}

No Brasil a educação especial tem como público alvo alunos com deficiência, transtornos globais de desenvolvimento (TGD) e altas habilidades/superdotação (AH/SD), definido conforme as legislaçóes de Política de Educação Especial. O Atendimento Educacional Especializado identifica, elabora, organiza e disponibiliza recursos pedagógicos e de acessibilidade que eliminam as barreiras de aprendizagem dos estudantes, considerando suas demandas específicas. O objetivo dele é garantir igualdade de condições para o acesso, participação e permanência de todos os estudantes com demandas específicas no ambiente escolar.

Outro fator importante para levamos em consideração no Atendimento Educacional 
Especializado (AEE) são as Salas de Recursos Multifuncionais: locais equipados com mobiliários e materiais didáticos para a oferta do atendimento da Educação Especial. Podemos encontrar na (SRM), recursos multissensoriais e tecnologia assistiva que possibilitam a utilização de diferentes tipos de linguagens e comunicaçóes alternativas.

As Salas de Recursos Multifuncionais são caracterizadas por possuírem uma grande quantidade de tecnologias que facilitam a acessibilidade dos alunos com necessidades especificas. De acordo com Fonseca (2015):

[...] A Sala de Recursos Multifuncionais é um espaço de aprendizagem e compreensão dos processos cognitivos, sociais e emocionais, visando à superação das dificuldades de aprendizagem e o desenvolvimento de diferentes possibilidades dos sujeitos, logo, uma investigação sobre a organização desse espaço, pode contribuir para identificar os desafios e as conquistas da escola no âmbito da inclusão. (FONSECA, 2015, p. 15).

A (SRM) deve disponibilizar recursos de apoio pedagógico para o atendimento às especificidades educacionais dos estudantes, público alvo, da educação especial matriculados no ensino regular (BRASIL, 2007). É nela que o professor pode aproximar o estudante da sua realidade tornando o conhecimento mais significativo, uma vez que as tecnologias têm despertado o interesse do aluno. O uso do computador e da internet na (SRM) pode contribuir com a inclusão de estudantes com deficiência, tornando-se uma ótima ferramenta pedagógica para a aprendizagem significativa, diversificada e contextualizada dos discentes. Essas tecnologias devem ser utilizadas pela escola de maneira planejada e articulada com as necessidades dos estudantes. $\mathrm{O}$ uso adequado dessas ferramentas tecnológicas potencializa as aprendizagens dos alunos, tornando-a mais efetiva.

As (TICs) podem criar possibilidades para a promoção da autonomia, criatividade e interatividade, favorecendo um ambiente de aprendizagem atrativo e desafiadores para alunos e professores. O computador e a internet possibilitam também o desenvolvimento de alunos com defasagens de aprendizagem, através dos recursos multimídia, tais como jogos educacionais, vídeos, animações entre outros. Segundo Fonseca (2015) apud Raiça (2008):

[...] as tecnologias no contexto da Educação Inclusiva são de grande importância quando são usadas de forma intencional para atender às necessidades educacionais específicas dos alunos face as suas demandas no âmbito intelectual, físico, sensorial e motor com repercussão nas dimensôes sócias afetivas (FONSECA, 2015, p. 38).

O uso das Tecnologias da Informação e Comunicação permite que o professor adapte exercícios e conteúdos conforme o potencial de cada indivíduo, possibilitando diversas formas de leitura e o aprimoramento da escrita. Em muitos casos, para os alunos com deficiência, as (TICs) podem ser o único dispositivo deles se expressarem e interagirem com as demais pessoas, possibilitando também o rompimento com o isolamento do estudante e permitindo que ele possa se comunicar com a sociedade independente de suas limitaçôes.

Por conseguinte, o discente pode utilizar o computador e a internet para construir algo do seu interesse, não usar apenas as (TICs) para receber uma informação. Por isso, a importância do uso das tecnologias educacionais aliada a um processo metodológico, contribuindo para a aprendizagem dos conteúdos curriculares e o desenvolvimento de habilidades (visuais, auditivas, motoras, raciocínio-lógico, atenção, concentração, autoestima, autodomínio, criatividade socializaçáo), relaçóes afetivas e sociais. É importante que o professor planeje suas aulas levando 
em consideração o contexto do aluno e o que tem significado para ele.

Para que o ensino com as ferramentas tecnológicas seja eficaz é preciso de professores capacitados para a utilização das (TICs). Infelizmente, podemos perceber ainda que muitos professores não estão preparados para utilizar o computador como ferramenta pedagógica na educação especial. A escola ainda não aprendeu a articular e a incorporar as novas linguagens ao fazer pedagógico, portanto, o uso dos recursos tecnológicos é um grande desafio. Sendo assim, faz necessário que o educador realize formação continuada para saber as tecnologias educacionais a seu favor na construção de novos saberes. De acordo com Buniotti (2014):

[...] é preciso oferecer ao professor uma formação inicial mais adequada para que ela tenha condiçóes de lidar com as tecnologias e usá-las para potencializar a sua prática docente; rever o currículo escolar, no sentido de rediscutir os conteúdos, objetivos e metodologia; repensar a forma como os discentes aprendem hoje, como eles se apropriam da linguagem tecnológica e quais habilidades e competências cognitivas e motoras serăo desenvolvidas com o uso do computador e da internet; e oferecer curso de formação continuada para que o professor esteja sempre estudando, pesquisando e vivenciando formas diferentes de trabalhar a integração das mídias no contexto pedagógico, no sentido de tornar os atos de ensinar e aprender um processo contextualizado, interativo e prazeroso (BUNIOTTI, 2014, p. 97).

Dessa maneira as tecnologias educacionais possibilitam o educador a trabalhar a leitura, produção de texto, a produção da escrita, o desenvolvimento de linguagem não verbal, usando imagens ampliadas. Permite ainda interpretar histórias através de filmes em audiodescrição, desenvolver habilidades de narrativas orais, utilizar dicionários online, livros de leituras, calendários e inúmeros símbolos e pranchas. $\mathrm{O}$ computador e a internet possibilitam um conjunto de hardware e software produzidos com a intenção de tornar o acesso mais fácil aos alunos com limitaçóes físicas, auditivas e visuais, permitindo o contato do estudante, através dos dispositivos de entrada de teclados virtuais, mouses especiais, software de acionamento de voz, também órteses e ponteiras para digitação, softwares de leitores de textos impressos, impressoras em braile, impressão em relevo, entre outros.

\section{Considerações finais}

As (TICs) podem ser usadas para valorizar as diversidades. Elas devem ser utilizadas para formar pessoas cada vez mais autônomas e independentes, além de serem usada para o desenvolvimento das necessidades de cada aluno. Existem vários softwares que podem ajudam a solucionar limitaçóes, atividades que antes eram impossíveis de serem realizadas, e com a utilização dessas ferramentas tornaram-se possíveis. As (TICs) não podem ser vista como algo opcional, mas como tecnologia fundamental para a formação do cidadáo pleno, pois seu uso é um direito fundamental. Dessa forma, as (TICs) possibilitam interromper a limitação, a impossibilidade e a incapacidade para permitir a capacidade, possibilidades e a competência para o aluno com deficiência. Ela gera o empoderamento da pessoa com necessidades especiais que passa a ser vista como uma pessoa capaz, que pode fazer algo como qualquer outra pessoa. Portanto, a escola precisa estar aberta e preparada para incorporar as tecnologias ao seu cotidiano. 


\section{Referências}

ALARCÃO. Isabel. Professores reflexivos em uma escola reflexiva. 8 ed. São Paulo: Cortez, 2011.

BRAVO, Solange de Fátima. O uso das tecnologias assistivas no Atendimento Educacional Especializado. In: Os desafios da escola pública paranaense na perspectiva do professor PDE. Caderno pedagógico/ Versão Online. Foz do Iguaçu: Governo do Estado, 2016.

BUNIOTTI, Daniel. O computador e a internet como instrumentos de aprendizagem nas salas de recurso. Universidade Tecnológica Federal do Paraná. Diretoria de pesquisa e pós-graduação. Especialização em Educação: métodos e técnicas de ensino. Monografia de Especialização. Medianeira, 2014

FONSECA, Janini Galvão. O Atendimento Educacional Especializado e o uso das tecnologias nas salas de recursos multifuncionais no Ensino Médio público do Distrito Federal. Dissertação de Mestrado. Universidade de Brasília/ UNB- Programa de Pós-Graduação em Educação. Brasília, 2015.

FONSECA, Selva Guimarães. Didática e prática de ensino de história: Experiências, reflexóes e aprendizados / Selva Guimarães Fonseca. Campinas, SP: Papirus, 2017.

IBGE. Diretoria de Pesquisas, Coordenação e Trabalho e Rendimento, Pesquisa Nacional por Amostra de Domicilios Contínua 2019. Disponível em: <https://educa.ibge.gov.br/jovens/ materias-especiais/20787-uso-de-internet-televisao-e-celularno-brasil.html> Acesso 08 jul. 2021.

LEITE, Sheila Cristiane Vilanova; SOUZA, Divanizia do Nascimento. O Uso do computador no processo de ensino-aprendizagem: um estudo na escola. In: SOUZA, Divanizia do Nascimento. Mídias na educação sob o olhar de professores autores. São Cristóvão: Editora UFS, 2014, p.73-101.

QUEIROZ, Artur; FERREIRA NETO, Elviro; CANUTO, Solange. Informática acessivel no Atendimento Educacional Especializado: uma experiência local. Disponível em $<\mathrm{https}$ :// www.editorarealize.com.br/revistas/conapesc/trabalhos/TRABALHO_EV126_MD1_SA4_ ID1097_18052019194054.pdf> Acesso dia 03/04/2020.

SANTOS, Jorge Henrique Vieira; FRANÇA, Lílian Cristina Monteiro. O computador como ferramenta pedagógica: In: SOUZA, Divanizia do Nascimento. Midias na educação sob o olhar de professores autores. São Cristóvão: Editora UFS, 2014, p. 43-72.

SOUZA, Rita de Cácia Santos. Educação especial em Sergipe do século XIX ao início do século XX: cuidar e educar para civilizar. São Cristóvão: Editora UFS, 2014. 